\title{
The changing living arrangements of young adults in the UK
}

Ann Berrington, Juliet Stone and Jane Falkingham

University of Southampton

\section{Introduction}

The transition to adulthood is increasingly being postponed and becoming less standardised. ${ }^{1,2}$ One of the key markers of the transition to adulthood is a move to independent living by leaving the parental home. ${ }^{3}$ In general, there has tended to be an increase in the age at which young people leave the parental home across Europe, although pervasive regional differences remain, ${ }^{4,5,6}$ with young adults in the UK tending to leave home comparatively early relative to their European counterparts. At the same time, recent attention in the UK has focused upon the increasing proportion of young adults who are living with their parents. ${ }^{7}$ The timing of and reasons for leaving the parental home differ according to socioeconomic circumstances. ${ }^{8,9}$ Some, often more privileged, young adults leave home to attend higher education at around ages 18-20. Other young adults may make planned departures, for example to take up employment or to live with a partner, while for other (often most disadvantaged) young adults, their pathways out of the parental home may be unplanned and more chaotic. ${ }^{10}$ In this article, we focus on the changing living arrangements of young adults over the past 20 years. During this period we have seen changes in the opportunities and constraints faced by young people in their transition to independent living.

First, we have seen considerable expansion in the higher educational system. The absolute number of full-time undergraduate students in the UK tripled between $1970 / 71$ and $2006 / 07$ (414,000 to 1,269,000), with females now outnumbering male undergraduates. ${ }^{11}$ Although more students are living at home while at university, they remain in the minority. ${ }^{12}$ Secondly, the collapse of the youth labour market in the $1980 \mathrm{~s}^{13}$ has been followed by a continuation of high youth unemployment rates, despite periods of relative economic buoyancy.
Patterns of leaving the parental home and transitions to independent living, partnership and family formation in the UK are now far more protracted and diverse than they were in the recent past. Over the past twenty years there have been significant changes in the institutional and structural context within which young adults make these transitions. This article examines changes over the past twenty years in the living arrangements of young men and women aged 16 to 34 years and how the proportions living with their parents differ by geographical region, education and economic activity. 
The recent recession has been accompanied by a sharp increase in unemployment rates among young adults. ${ }^{14}$ Furthermore, there appears to be an increasing focus on those who are not in education, employment or training (the so-called NEETs). ${ }^{15}$ While local unemployment difficulties may force young people to move out of their home region for employment, many without employment will lack the necessary financial autonomy to establish an independent household. This lack of employment has been compounded by a change in housing stock and affordability. First-time buyers have found it increasingly difficult to enter the housing market with average 'house price to individual income' ratios increasing from around 3.0 to greater than 5.0. ${ }^{16}$ All three of these contextual factors are often cited as partial explanations for the postponement of marriage and family formation in contemporary society. This postponement is also, however, a reflection of the changing roles of men and women and changing expectations of normative ages for partnership and family formation. It is unclear the extent to which remaining in (or returning to) the parental home is an outcome of choice rather than constraint for these 'emergent adults'. ${ }^{17}$

\section{Aims}

This article aims to explore, over the past two decades, the key changes in the living arrangements of young adults aged 16-34. We document the extent to which the living arrangements of young adults, including the percentage living in the parental home, have changed over the past 20 years. We identify current differentials in the percentage living with their parent(s) by country, region, economic activity status and highest educational qualification.

\section{Data source}

\section{The Labour Force Survey}

The Labour Force Survey (LFS) is a large, nationally representative, sample survey of households living at private addresses and in NHS accommodation in the UK. ${ }^{18}$ The LFS will consistently underestimate the percentage of young adults living away from the parental home since it does not record those living in communal establishments such as halls of residence, prisons and hostels. For this age group, the underestimation is largely among those in their late teens and very early twenties attending higher education. Data from the 2001 Census suggests that one-quarter of students aged 19 are living in communal establishments, compared to 14 per cent of those aged 20-24 and less than five per cent of those aged $25-29 .{ }^{19}$

The design of the LFS changed from an annual to a quarterly rotating sample design in 1992 (1994 in Northern Ireland). Household addresses remain in the sample for five quarters before being replaced. In 2006, the survey moved from using seasonal quarters to calendar quarters. Currently, about 50,000 households are included in each quarter. In this research we use data from the 1988 annual LFS, the 1998 Autumn quarter household LFS, and the 2008 October-December quarter household LFS, to provide comparisons over a twenty-year period.

The current sampling frame for Britain south of the Caledonian Canal is the postcode address file. For the area north of the Caledonian Canal, a random sample is taken from the published telephone directory. The Northern Ireland sampling frame is currently based on the Valuation List used for rating purposes. The analyses shown below are weighted using weights produced by the Office for National Statistics (ONS) to adjust for differential non-response and to make the sample representative of the UK household population. For the survey years 1992 and onwards, ONS has produced both an individual and a household version of the LFS. The key difference between these two datasets is that the household dataset includes a common household weighting factors, which are the same for every member of a household. The latter thus provides consistent estimates, for example of the number of married men and women in the sample, and is used here for 1998 and 2008.

\section{Methods}

\section{Identifying household and family units}

The definitions of a 'household' and 'family unit' used in the LFS are shown in Box one together with information on how the 'household head', 'household reference person' and 'family unit head' are derived. These definitions can be used consistently across LFS surveys to identify those who are living either as the child of a household head (or household reference person) or living as the child of a family unit head. ${ }^{20}$ Hence, we can identify the changing proportions of young adults living in the parental home for 1988, 1998 and 2008. We can also identify for those not living in the parental home, whether they are living with a partner and/or child, or if they are living in a single person family unit. The latter might be living alone, sharing with other relatives (for example, a sibling), or sharing with other unrelated individuals. Hence we are able to classify young adults according to Figure 1.

\section{Geographical region}

The LFS identifies which country and government office region within which the respondent resides. The region code in the LFS also separately identifies large metropolitan areas which is important given that local opportunities for jobs, education etc. may be more numerous and varied in these areas than in smaller towns or in rural areas. In turn, these factors may influence the living arrangements of young adults, particularly in terms of leaving the parental home. The results for region are presented for 2008 only, as changes in the boundaries of geographical areas since 1988 prevent meaningful comparisons over time.

\section{Socio-economic characteristics}

We investigate the living arrangements of young people according to two key socio-economic background variables: economic activity and educational attainment. Current economic activity is defined in four categories: Employment, Unemployed, Student ${ }^{21}$ and Inactive. The reasons for inactivity vary by gender, with women most likely to be inactive due to looking after the home/family and men more likely to be inactive due to sickness. Highest educational qualification is defined in five categories: Degree or higher education, 'A' levels or equivalent, GCSEs grades A-C or equivalent, Other qualifications and No qualifications. The 'other category' is partly made up from those who have GCSEs below grade C or CSEs below grade 1, but also includes undefined qualifications. ${ }^{22}$

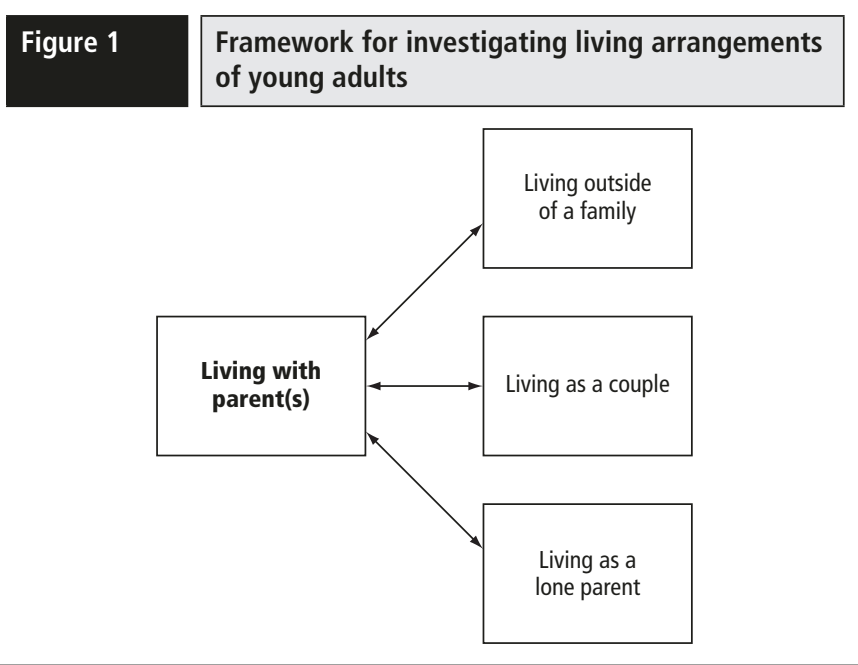




\section{Box one}

\section{Labour Force Survey definitions of Households, Family Units, Household Head and Household Reference Person}

\section{Household}

'A household comprises of a single person, or a group of people living at the same address who have the address as their only or main home. They also share one main meal a day or share the living accommodation (or both). Most households contain one family unit but it is not uncommon for a household to contain two or more family units.'

\section{Family unit}

'A family unit can comprise either a single person, or a married/cohabiting couple, or a married/cohabiting couple and their never-married children who have no children of their own living with them, or a lone parent with such children. Also, LFS family units can include nondependent 'children' (who may be adults by their age) provided they have never-married and have no children of their own living with them. People who live with their parents and are married or have children of their own living with them are treated (with their spouse/children) as being a separate family unit from their parents. Other examples of households that comprise two or more family units include two or more friends living together, or two or more siblings living together (if neither of their parents is living in the household).

\section{Household head}

'In a household where there is one adult only, that adult is the head of their household $(\mathrm{HoH})$. If there are two adults of the opposite sex living together as a married or cohabiting couple, the husband/male partner is the HoH. Otherwise, the oldest male householder, or the husband/male partner of the oldest female householder, is the $\mathrm{HoH}$. Otherwise, the oldest female householder is the HoH.'

\section{Household reference person}

'The household reference person is the householder, which is the household member who owns the accommodation; or is legally responsible for the rent; or occupies the accommodation as reward of their employment, or through some relationship to its owner who is not a member of the household. If there are joint householders, the one with the highest income is the household reference person. If their income is the same, then the eldest one is the household reference person. The household reference person (HRP) was introduced into the LFS in 2001, in line with other ONS household surveys, to replace the head of household. In about 90 per cent of households the $\mathrm{HoH}$ and HRP are the same person. In over 90 per cent of cases where they are not the same person, the HRP is the spouse or partner of the HoH. There are more female HRPs than female HoHs and HRPs tend to be slightly younger.'

\section{Family unit head}

'In a one-person family unit, that person is the head of their family unit. In a mixed-sex couple, the male partner is the head of the family unit. In a lone parent family, the lone parent is the head of the family unit. In a civil partnership, if one of the civil partners is the household reference person (HRP) that partner is the head of the family unit. If neither civil partner is the HRP (because someone else in the household is the HRP), the older partner is the head of the family unit. In same-sex cohabiting couples, the two partners are treated as separate family units and each partner is the head of their family unit.

In a household comprising two or more family units, a person who is the head of their family unit will not necessarily be the head of their household, or the household reference person.'

Source: ONS LFS User Guide no. 8

\section{Results}

The results below are presented in three parts: first, the pattern of living with parents or away from the parental home by single year of age is investigated for 1988, 1998 and 2008. Second, we investigate for the period 1988-2008, the changing distribution of young people in terms of the percentage remaining at home, living away from home in a new family (either as a couple or a lone parent) or outside a family. Third, differentials in the proportions living in the parental home are investigated according to geographical region, current economic activity and highest educational qualification.

\section{Living in the parental home}

Figure 2 shows, amongst the private residence population of the UK, the percentage of males and females living with a parent, by single year of age, in the three years, 1988, 1998 and 2008. The proportion living in the parental home declines rapidly from the late teens to the late twenties before levelling off. At every age, females are more likely to be living outside of the parental home than males. Over the past twenty years, but particularly in the earlier decade, between 1988 and 1998, there was a clear change in the pattern of the graph with a decisive drop in the proportions living with parents after age 18, associated with increased take up of higher education. Between 1998 and 2008 a slightly different change occurred for males and females. For males, the drop in co-residence with parents in the late teens continued to increase, but for females there was a small reversal of this trend. For those in their mid twenties to mid thirties, there has been a consistent, albeit small, increase in the proportion of young adults living with their parents over the past 20 years.

\section{Changing distribution of living arrangements}

In Table 1, we show for each age group, ${ }^{23}$ the percentage distribution of males and females living either with a parent or outside the parental home in a new family (either with a partner, or as a lone parent), or away from the parental home but living outside of a family. The latter could be living alone, or sharing accommodation (either with other relatives such as a sibling, or with unrelated individuals). The figures are given for 1988, 1998 and 2008 with the absolute percentage change in each decade shown in the final two columns. Absolute changes over time where confidence intervals for individual years do not overlap are highlighted in bold.

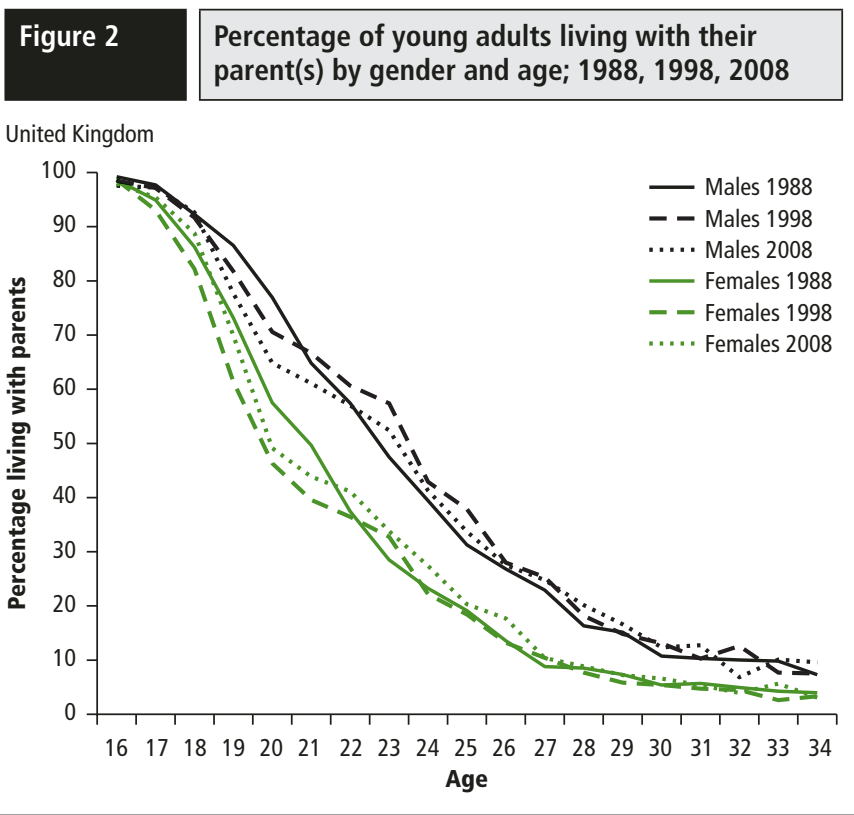




\begin{tabular}{|c|c|c|c|c|c|c|c|c|}
\hline \multirow{2}{*}{$\begin{array}{l}\text { Type of living arrangements } \\
\text { by age group }\end{array}$} & \multicolumn{2}{|c|}{1988} & \multicolumn{2}{|c|}{1998} & \multicolumn{2}{|c|}{2008} & \multicolumn{2}{|c|}{ Absolute change } \\
\hline & $\begin{array}{c}(n) \\
\text { per cent }\end{array}$ & $\begin{array}{l}95 \% \text { confidence } \\
\text { interval }\end{array}$ & $\begin{array}{c}(\mathrm{n}) \\
\text { per cent }\end{array}$ & $\begin{array}{c}95 \% \text { confidence } \\
\text { interval }\end{array}$ & $\begin{array}{c}(\mathrm{n}) \\
\text { per cent }\end{array}$ & $\begin{array}{c}95 \% \text { confidence } \\
\text { interval }\end{array}$ & 1988-1998 & 1998-2008 \\
\hline $20-21$ & \multicolumn{2}{|c|}{$(n=2,231)$} & \multicolumn{2}{|c|}{$(n=1,345)$} & \multicolumn{2}{|c|}{$(n=1,167)$} & & \\
\hline With parent(s) & 70.8 & $(68.8,72.7)$ & 68.6 & $(66.2,71.1)$ & 62.9 & $(60.0,65.7)$ & -2.1 & -5.8 \\
\hline In a couple & 6.8 & $(5.8,8.0)$ & 7.8 & $(6.5,9.4)$ & 8.8 & $(7.3,10.6)$ & 1.0 & 1.0 \\
\hline As a lone parent & 0.7 & $(0.4,1.2)$ & 0.0 & $(0.0,0.0)$ & 0.1 & $(0.0,0.6)$ & -0.7 & 0.1 \\
\hline Outside a family & 21.8 & $(20.0,23.6)$ & 23.5 & $(21.3,26.0)$ & 28.2 & $(25.6,31.0)$ & 1.8 & 4.7 \\
\hline $22-24$ & \multicolumn{2}{|c|}{$(\mathrm{n}=3,567)$} & \multicolumn{2}{|c|}{$(n=2,098)$} & \multicolumn{2}{|c|}{$(n=1,695)$} & & \\
\hline With parent(s) & 48.1 & $(46.4,49.8)$ & 53.3 & $(51.1,55.4)$ & 50.1 & $(47.7,52.5)$ & 5.2 & -3.2 \\
\hline In a couple & 23.4 & $(22.0,24.9)$ & 24.1 & $(22.3,26.0)$ & 24.5 & $(22.5,26.6)$ & 0.7 & 0.4 \\
\hline As a lone parent & 0.7 & $(0.6,1.2)$ & 0.0 & $(0.0,0.3)$ & 0.1 & $(0.0,0.4)$ & -0.8 & 0.1 \\
\hline Outside a family & 27.7 & $(26.2,29.3)$ & 22.6 & $(20.8,24.5)$ & 25.3 & $(23.2,27.5)$ & -5.1 & 2.7 \\
\hline $25-29$ & \multicolumn{2}{|c|}{$(n=5,674)$} & \multicolumn{2}{|c|}{$(n=4,461)$} & \multicolumn{2}{|c|}{$(n=3,077)$} & & \\
\hline With parent(s) & 22.7 & $(21.6,23.8)$ & 24.3 & $(23.0,25.5)$ & 24.5 & $(23.0,26.1)$ & 1.6 & 0.3 \\
\hline In a couple & 53.9 & $(52.6,55.3)$ & 52.6 & $(51.2,54.1)$ & 47.7 & $(45.9,49.5)$ & -1.3 & -5.0 \\
\hline As a lone parent & 0.9 & $(0.7,1.2)$ & 0.3 & $(0.2,0.5)$ & 0.3 & $(0.2,0.6)$ & -0.6 & 0.0 \\
\hline Outside a family & 22.5 & $(21.4,23.6)$ & 22.9 & $(21.6,24.1)$ & 27.5 & $(25.9,29.1)$ & 0.4 & 4.6 \\
\hline $30-34$ & \multicolumn{2}{|c|}{$(n=5,423)$} & \multicolumn{2}{|c|}{$(n=5,375)$} & \multicolumn{2}{|c|}{$(n=3,122)$} & & \\
\hline With parent(s) & 9.7 & $(8.9,10.5)$ & 10.2 & $(9.4,11.0)$ & 10.3 & $(9.3,11.4)$ & 0.5 & 0.1 \\
\hline In a couple & 73.9 & $(72.7,75.1)$ & 70.9 & $(69.6,72.1)$ & 69.9 & $(68.2,71.5)$ & -3.0 & -1.0 \\
\hline As a lone parent & 1.0 & $(0.8,1.4)$ & 0.9 & $(0.7,1.0)$ & 0.7 & $(0.5,1.1)$ & -0.1 & -0.2 \\
\hline Outside a family & 15.4 & $(14.5,16.5)$ & 18.1 & $(17.1,19.2)$ & 19.1 & $(17.7,20.6)$ & 2.7 & 1.0 \\
\hline
\end{tabular}

Note: unweighted $\mathrm{n}$ and weighted percentage.

Absolute changes over time where confidence intervals for individual years do not overlap are shown in bold.

Data source: Labour Force Survey, Annual 1988, Quarterly Sep-Nov 1998 and Oct-Dec 2008

\begin{tabular}{|c|c|c|c|c|c|c|c|c|}
\hline \multirow{2}{*}{$\begin{array}{l}\text { Type of living arrangements } \\
\text { by age group }\end{array}$} & \multicolumn{2}{|c|}{1988} & \multicolumn{2}{|c|}{1998} & \multicolumn{2}{|c|}{2008} & \multicolumn{2}{|c|}{ Absolute change } \\
\hline & $\begin{array}{c}(\mathrm{n}) \\
\text { per cent }\end{array}$ & $\begin{array}{l}95 \% \text { confidence } \\
\text { interval }\end{array}$ & $\begin{array}{c}\text { (n) } \\
\text { per cent }\end{array}$ & $\begin{array}{l}95 \% \text { confidence } \\
\text { interval }\end{array}$ & $\begin{array}{c}\text { (n) } \\
\text { per cent }\end{array}$ & $\begin{array}{c}95 \% \text { confidence } \\
\text { interval }\end{array}$ & 1988-1998 & 1998-2008 \\
\hline $20-21$ & \multicolumn{2}{|c|}{$(n=2,395)$} & \multicolumn{2}{|c|}{$(n=1,410)$} & \multicolumn{2}{|c|}{$(n=1,206)$} & & \\
\hline With parent(s) & 53.5 & $(51.4,55.6)$ & 43.0 & $(40.4,45.6)$ & 46.4 & $(43.649 .3)$ & -10.6 & 3.4 \\
\hline In a couple & 16.9 & $(15.4,18.5)$ & 24.0 & $(21.8,26.3)$ & 21.7 & $(19.4,24.2)$ & 7.1 & -2.3 \\
\hline As a lone parent & 6.2 & $(5.3,7.3)$ & 8.0 & $(6.8,9.5)$ & 7.3 & $(6.0,8.8)$ & 1.8 & -0.7 \\
\hline Outside a family & 23.4 & $(21.6,25.3)$ & 25.0 & $(22.8,27.4)$ & 24.6 & $(22.1,27.2)$ & 1.6 & -0.5 \\
\hline $22-24$ & \multicolumn{2}{|c|}{$(n=3,686)$} & \multicolumn{2}{|c|}{$(n=2,385)$} & \multicolumn{2}{|c|}{$(n=1,824)$} & & \\
\hline With parent(s) & 29.7 & $(28.2,31.2)$ & 30.0 & (28.3 32.0) & 34.0 & $(31.8,36.2)$ & 0.3 & 4.0 \\
\hline In a couple & 39.5 & $(37.8,41.1)$ & 40.3 & $(38.3,42.3)$ & 39.5 & $(37.2,41.8)$ & 0.8 & -0.8 \\
\hline As a lone parent & 8.0 & $(7.1,8.9)$ & 10.2 & $(9.1,11.4)$ & 11.2 & $(9.9,12.7)$ & 2.2 & 1.0 \\
\hline Outside a family & 22.9 & $(21.5,24.3)$ & 19.4 & $(17.8,21.1)$ & 15.3 & $(13.7,17.1)$ & -3.5 & -4.1 \\
\hline $25-29$ & \multicolumn{2}{|c|}{$(n=6,030)$} & \multicolumn{2}{|c|}{$(n=5,100)$} & \multicolumn{2}{|c|}{$(n=3,562)$} & & \\
\hline With parent(s) & 11.6 & $(10.8,12.5)$ & 10.7 & $(9.9,11.6)$ & 12.8 & $(11.7,13.9)$ & -0.9 & 2.1 \\
\hline In a couple & 64.0 & $(62.7,65.2)$ & 61.6 & $(60.2,62.9)$ & 62.5 & $(60.9,64.0)$ & -2.4 & 0.9 \\
\hline As a lone parent & 9.2 & $(8.5,10.0)$ & 12.5 & $(11.7,13.4)$ & 11.0 & $(10.1,12.0)$ & 3.3 & -1.5 \\
\hline Outside a family & 15.2 & $(14.3,16.1)$ & 15.2 & $(14.2,16.2)$ & 13.7 & $(12.6,14.9)$ & 0.0 & -1.5 \\
\hline $30-34$ & \multicolumn{2}{|c|}{$(n=5,724)$} & \multicolumn{2}{|c|}{$(n=5,866)$} & \multicolumn{2}{|c|}{$(n=3,540)$} & & \\
\hline With parent(s) & 4.9 & $(4.3,5.5)$ & 4.1 & $(3.6,4.6)$ & 4.9 & $(4.2,5.6)$ & -0.8 & 0.8 \\
\hline In a couple & 77.3 & $(76.2,78.4)$ & 73.0 & $(71.9,74.1)$ & 72.6 & $(71.2,74.1)$ & -4.3 & -0.4 \\
\hline As a lone parent & 10.3 & $(9.5,11.2)$ & 13.9 & $(13.1,14.8)$ & 11.9 & $(10.9,12.9)$ & 3.6 & -2.0 \\
\hline Outside a family & 7.5 & $(6.8,8.2)$ & 9.0 & $(8.3,9.8)$ & 10.6 & $(9.6,11.7)$ & 1.5 & 1.6 \\
\hline
\end{tabular}

Note: unweighted $\mathrm{n}$ and weighted percentage.

Absolute changes over time where confidence intervals for individual years do not overlap are shown in bold.

Data source: Labour Force Survey, Annual 1988, Quarterly Sep-Nov 1998 and Oct-Dec 2008 
In the earlier decade (1988 to 1998) there was a marked shift towards leaving home at younger ages, especially for females. In the subsequent decade (1998 to 2008), this move towards living away from the parental home continued for men aged 20-21, but for females was counteracted among women by a decrease in the number living in a new family. At older ages there has been an increase in the proportions of young adults either living with their parents or living away from the parental home and outside a family and a corresponding decline in the proportions living in a couple. These trends reflect the postponement of entry into partnership and parenthood.

Between 1988 and 1998 there was an increase in the percentage of women in their twenties and early thirties who were living as a lone parent, but this increase did not persist over the subsequent decade. This apparent stabilisation of the prevalence of lone motherhood emerges in the context of delayed fertility. LFS data indicate that in 1998, 49.7 per cent of women aged $20-34$ had at least one child living with them, falling to 43.0 per cent in 2008 .

The remainder of this article focuses on young adults living with their parents.

\section{Geographical differences}

Next we discuss regional differentials in the proportion of young adults living with their parents. Sample size issues mean that we consider a broader age range - those aged 22-29. Map 1 and Map 2 show the percentage of young people in this age group living in the parental home by Country, Government Office Region and Metropolitan area. In order to allow comparison of the relative distribution of different living arrangements in males and females, the data are presented in quartiles rather than using an absolute cut-off value for percentage living with parents. The cut-offs between each quartile are placed so that there is an equal number of regions in each of the four groups.

Regional differences in current living arrangements are difficult to interpret since they are the result of a number of forces including:

- the propensity of young people to leave home to find work or attend higher education - which will be influenced by the presence of a buoyant labour market or of higher institutions in the area

- the propensity for young, single adults to move into an area, for example, for the purposes of taking up employment or education

- the propensity of young people to leave home to form a family and

- the propensity of families to move to an area

There are also regional differences in the extent to which students stay in the region in which they studied for their further or higher education ${ }^{24}$ or return home for example, due to proximity to job market.

These complex processes underlying regional differences in living arrangements are difficult to disentangle using a cross-sectional data source such as the Labour Force Survey, particularly with regard to patterns of migration within and between regions. However, we refer to existing statistics and longitudinal research on, for example, the geographical origins and destinations of young adults entering higher education ${ }^{24}$ and more general patterns of migration within the $\mathrm{UK}^{25}$ to support the interpretation of our findings.

Areas with the lowest percentage of young adults living in the parental home include inner London, South Yorkshire and West Yorkshire. This relates in part to the proximity of higher education institutions: according to Higher Education Statistics Agency statistics, ${ }^{24}$ these are among the regions with the largest absolute numbers of higher education students. Census data also show net gains of students for university towns in Yorkshire, with losses from Cumbria, North Yorkshire and much of the
South West, Gloucestershire and Wiltshire ${ }^{25}$. More generally however, Dennett and Stillwell document the flow of 16-29 year olds away from rural areas towards large urban areas in search of employment opportunities, and that London remains a key destination on leaving higher education. ${ }^{26}$

The proportion living with a parent is highest in Northern Ireland, ${ }^{27}$ Strathclyde, the West Midlands Metropolitan County and outer London (and among men non metropolitan parts of the North East). We might speculate that the pattern in outer London is related to the potential for young adults to remain living in the parental home while exploiting the employment and education opportunities available in neighbouring inner London. In Northern Ireland, the high proportion living with their parents is likely to be related in part to a lack of geographical mobility - for example, 2001 Census data show that, at region/country level, Northern Ireland had the smallest proportion of residents who were known to have moved within the UK during the previous year. ${ }^{25}$

The Strathclyde region includes Glasgow City, which saw negative net migration within Scotland and the UK in the years prior to $2001,{ }^{28}$ in particular among those in their twenties and thirties. In contrast, the City of Edinburgh saw positive net migration during the same period. ${ }^{29}$ This implies that young people leaving the parental home in Glasgow tend to leave the city, but independent young adults are relatively unlikely to move there, leading to a larger proportion of the remaining population living with their parents. The region also includes more rural areas such as Argyll and Bute, which showed a similar pattern of negative net migration at younger ages (16-24 years), suggesting a move away to participate in higher education.

\section{Economic activity}

We now explore how living with parents differs according to current economic activity. Figures 3A, 3B, 3C and 3D, show for each age group, the percentage living at home among employed, unemployed, students and those who are otherwise economically inactive. It is important to note that for many females economic inactivity will be associated with childrearing and hence these women are more likely to have left home and to have a young family. For males, economic inactivity will be associated with ill health and other reasons for inactivity. Among those aged 20-24, students and those who are unemployed are more likely to be living away from home than are the employed. Economically

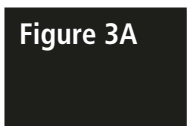

Percentage of young adults aged 20-21 living with their parent(s) according to economic activity in 1988 and 2008

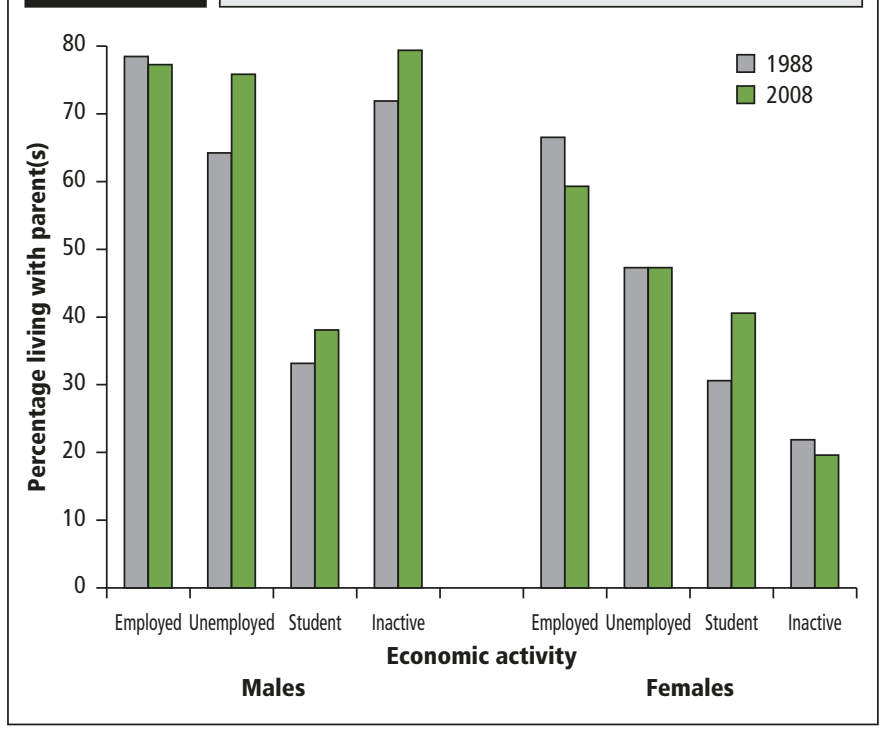




\section{Map 1}

United Kingdom

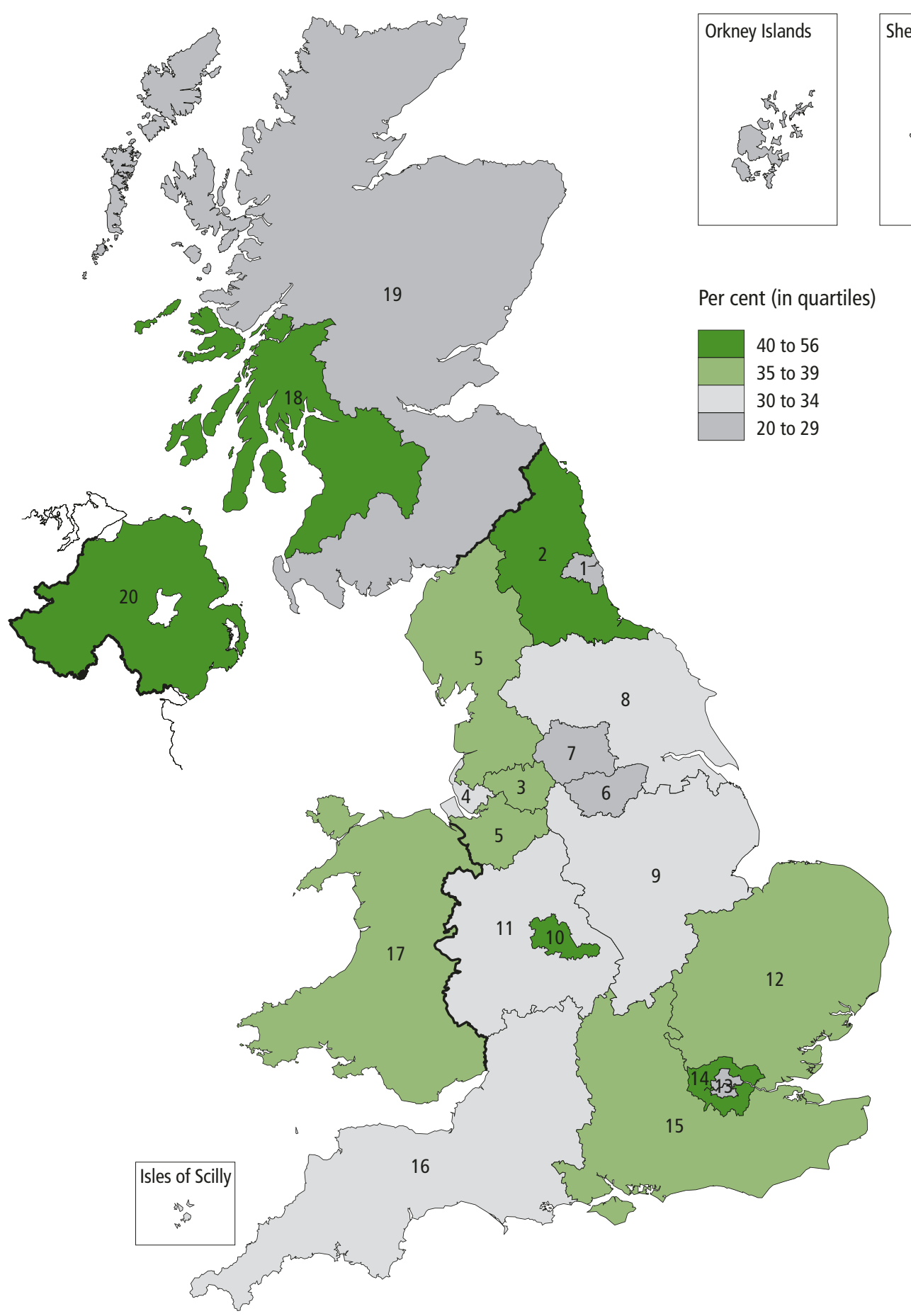

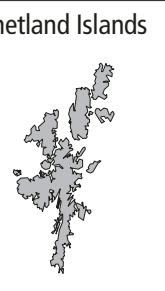

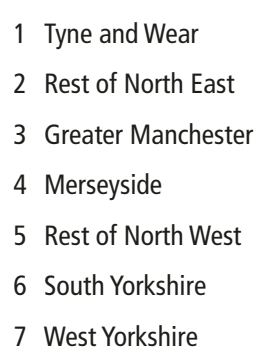

8 Rest of Yorkshire and The Humber
9 East Midlands
10 West Midlands Metropolitan County
11 Rest of West Midlands
12 East of England
13 Inner London
14 Outer London

15 South East

16 South West

17 Wales

18 Strathclyde

19 Rest of Scotland

20 Northern Ireland

1 Areas are based on countries, Government Office Regions, metropolitan counties, Inner and Outer London and groups of council areas. Source: Quarterly UK Labour Force Survey household dataset, Oct-Dec 2008, Office for National Statistics 


\section{Map 2}

United Kingdom
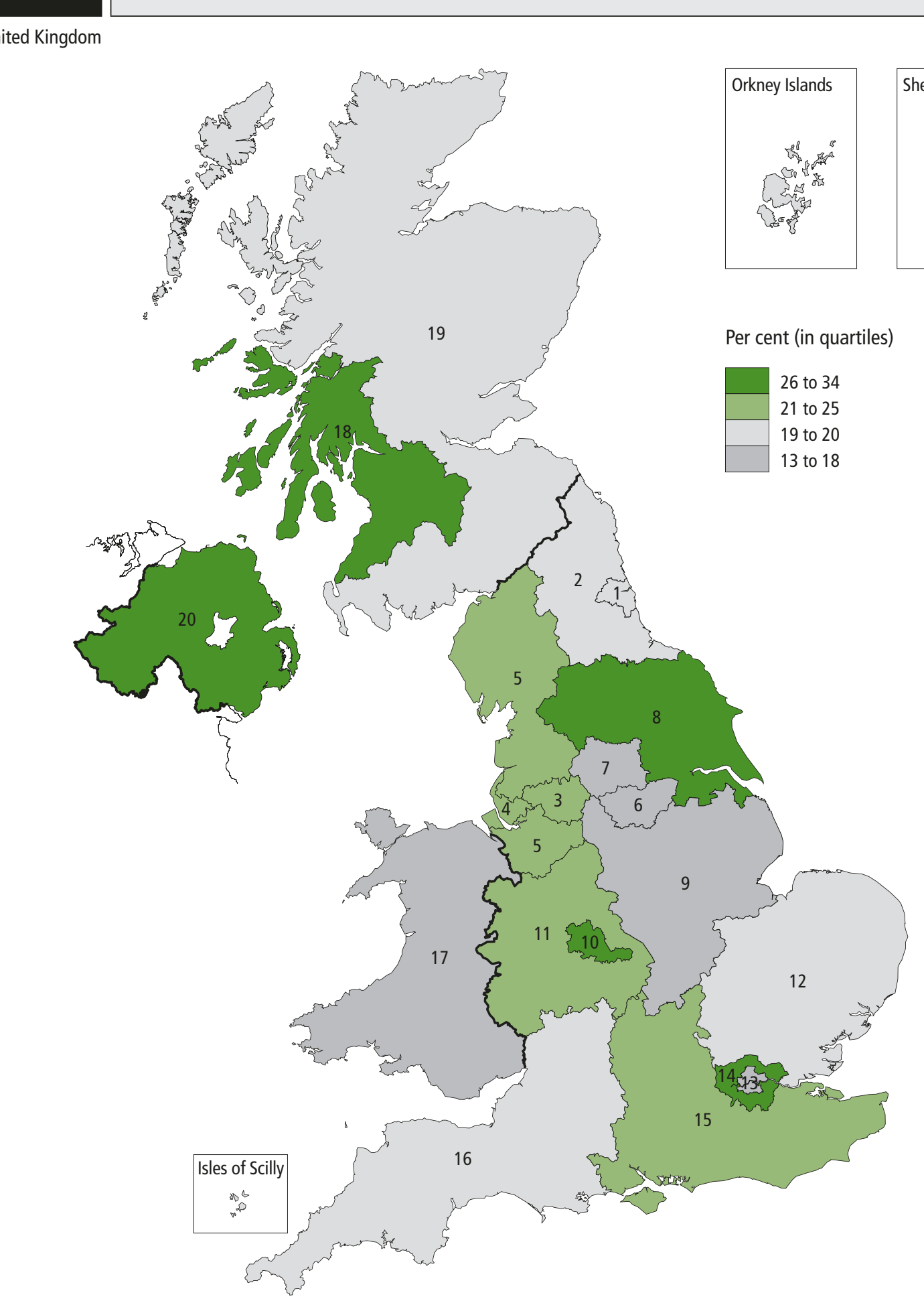

8 Rest of Yorkshire and The Humber

9 East Midlands

10 West Midlands Metropolitan County

11 Rest of West Midlands

12 East of England

13 Inner London

14 Outer I ondon
15 South East

16 South West

17 Wales

18 Strathclyde

19 Rest of Scotland

20 Northern Ireland

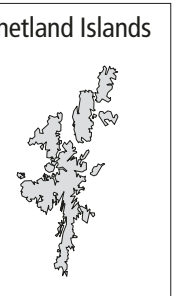

1 Tyne and Wear

1 Areas are based on countries, Government Office Regions, metropolitan counties, Inner and Outer London and groups of council areas. Source: Quarterly UK Labour Force Survey household dataset, Oct-Dec 2008, Office for National Statistics 

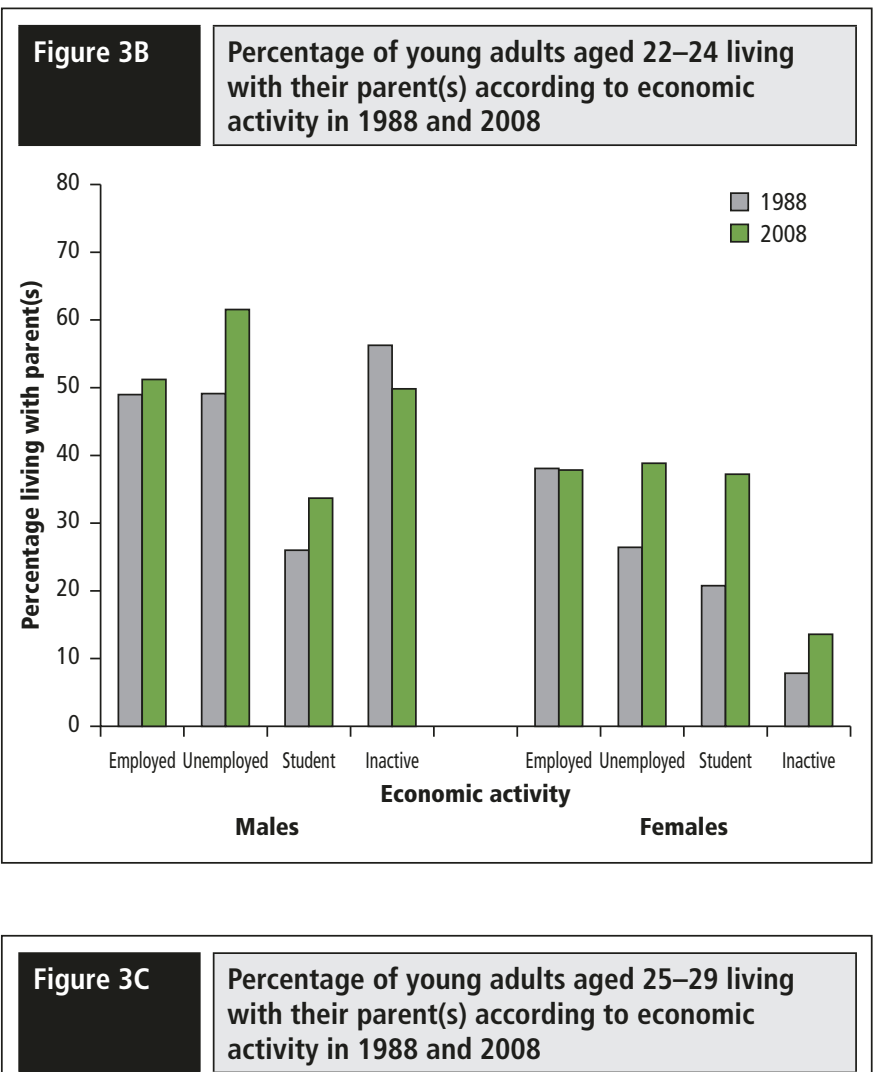

Percentage of young adults aged 25-29 living with their parent(s) according to economic activity in 1988 and 2008

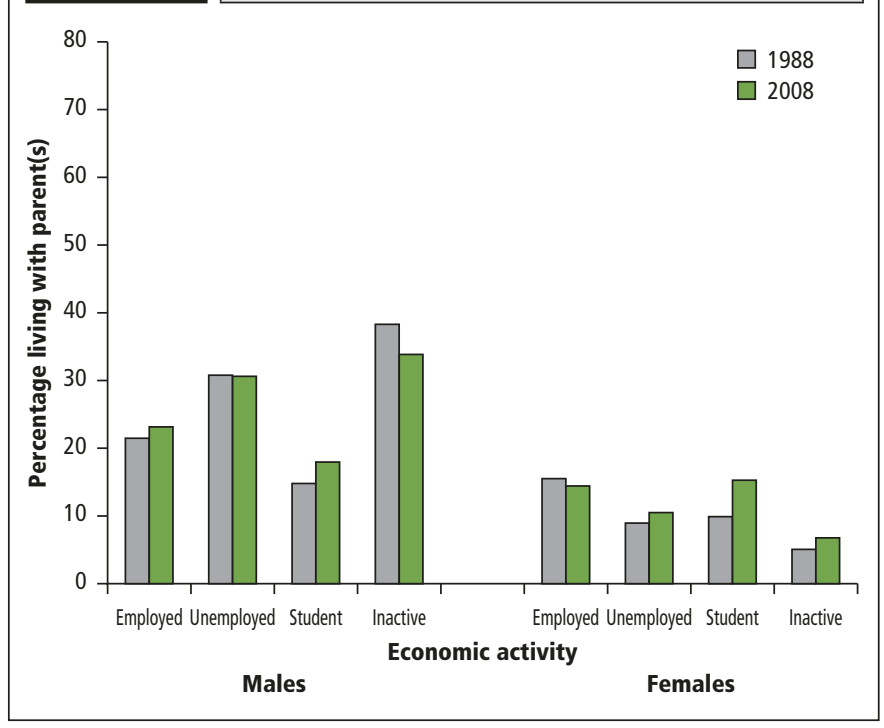

inactive men are very likely to be living at home. From age 22 years onwards however, unemployed young men are more likely than those in employment to be living at home and this pattern has become stronger over the past 20 years.

\section{Educational attainment}

Figures 4A, 4B and 4C show, for each age group (22-24, 25-29 and 30-34), the percentage of males and females living in the parental home in 1988 and 2008, according to highest educational qualification. For men in all age groups, those with higher levels of education are generally less likely to be living with their parents. The educational differences for men are more obvious for those in their late twenties and early thirties. Furthermore, between 1988 and 2008, men with no qualifications fell even further behind in terms of leaving home, with the percentage living with their parents at age $30-34$, increasing from 16 per cent to 27 per cent.

Figure 3D

Percentage of young adults aged 30-34 living with their parent(s) according to economic activity in 1988 and 2008

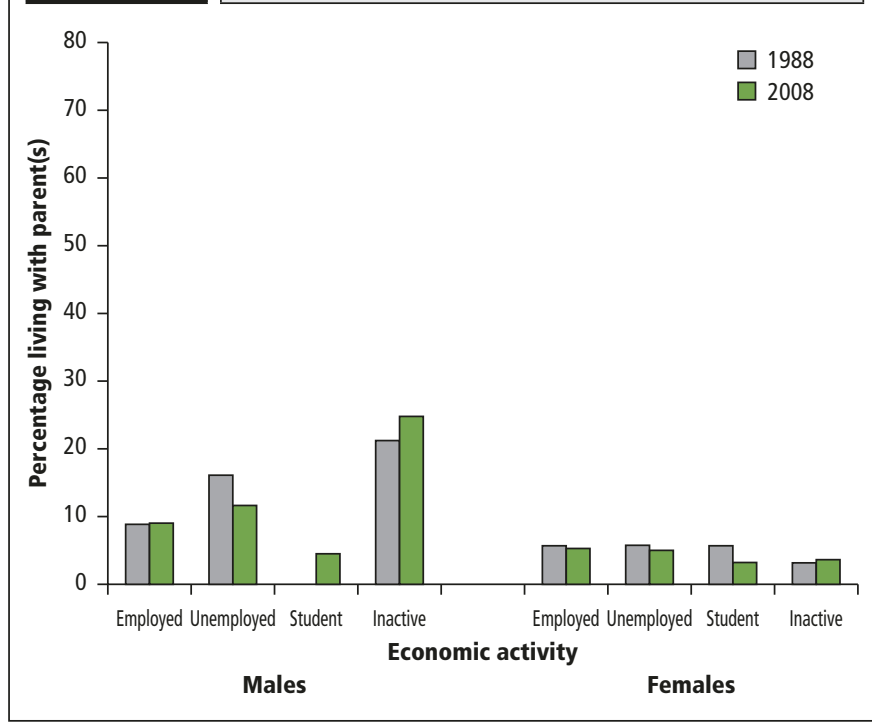

Source: Labour Force Survey, Annual 1988, Quarterly Oct-Dec 2008

For women, the pattern by education changes with age. At ages 22-24, the proportion living within the parental home in 2008 is highest for those with degrees and higher level qualifications and lowest for those with no qualifications. Among women in their later twenties, the proportions are fairly similar according to educational qualification (although the proportion with higher levels education who were living with their parents increased between 1988 and 2008). By their early thirties, however, women with higher educational qualifications are much less likely to be living within the parental home as compared with those with no qualifications (four per cent compared with 11 per cent).

As seen in Figures 4A, 4B and 4C there has been a clear trend towards more co-residence with parents in almost all educational groups. As previously noted the trend is greatest for those lacking qualifications.

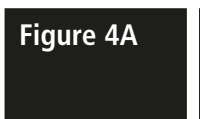

Percentage of males and females aged 22-24 living with parent(s) in 1988 and 2008 according to highest educational qualification

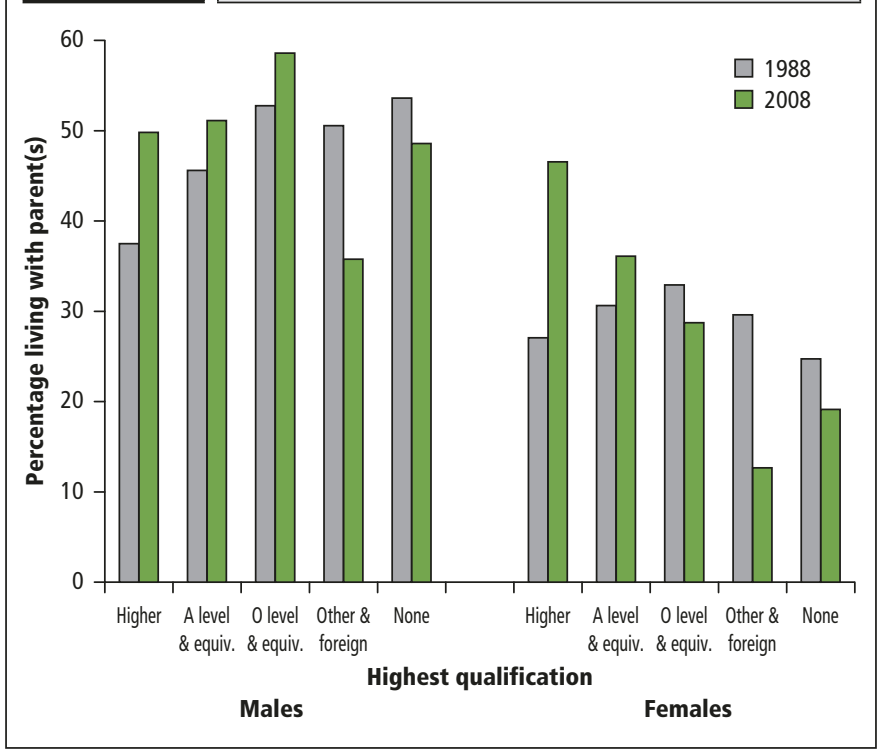




\section{Figure 4B}

Percentage of males and females aged 25-29 living with parent(s) in 1988 and 2008 according to highest educational qualification

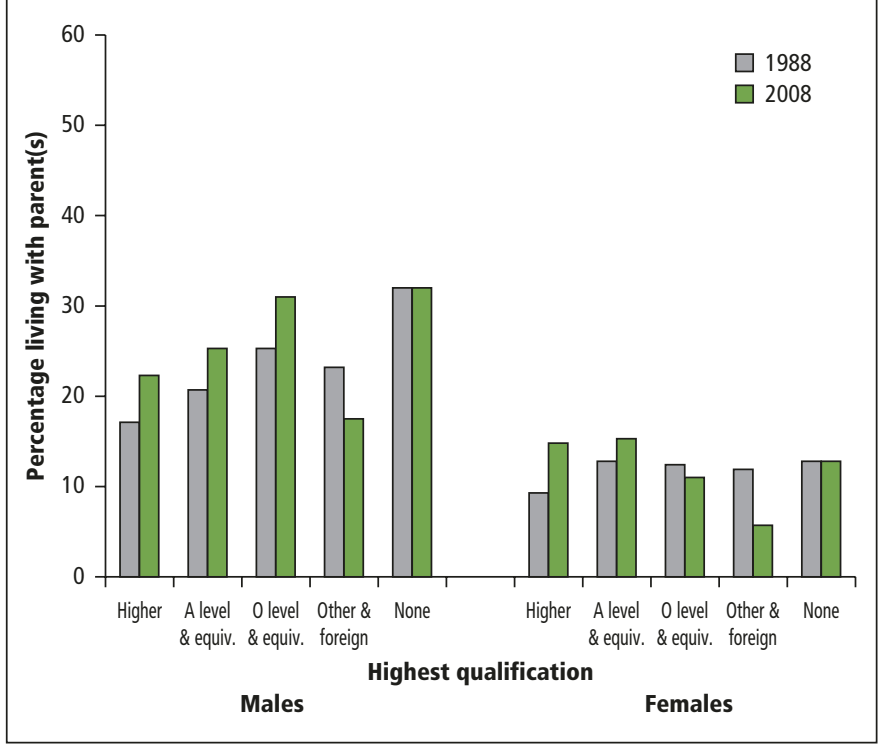

Figure 4C

Percentage of males and females aged 30-34 living with parent(s) in 1988 and 2008 according to highest educational qualification

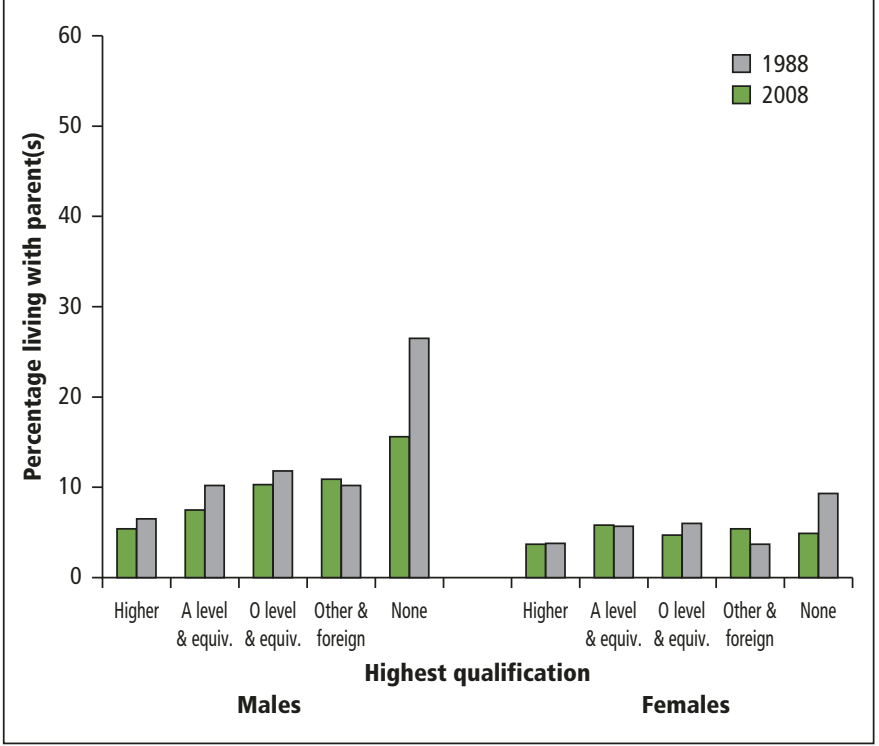

Source: Labour Force Survey, Annual 1988, Quarterly Oct-Dec 2008

The one group where a lower proportion is residing with their parents is the 'other' qualifications group. This divergence is likely to be due to those obtaining their qualifications overseas being classified as having 'foreign' qualifications, which have been placed in the 'other' group. Many such migrants in their twenties and early thirties will have left their parents behind. In other words, the composition of the 'other' qualifications group is increasingly made up of international migrants who are less likely to be co-resident with their parents.

\section{Discussion}

Over the whole age range, 16-34, there has been virtually no change over the past 20 years in the overall percentage of males and females living with a parent. But underlying this seeming stability are counteracting trends in different age groups; younger men and women have become less likely to live with their parents over time but those in their mid-twenties and older have become more likely to live with their parents.

It is difficult to assess from cross-sectional data the extent to which this pattern is a reflection of an age effect versus (or in addition to) a cohort effect. It is also unclear whether (and to what extent) it relates to increased returning home. However, the patterns by highest educational qualification suggest that, over the past decade, more of those with degree level qualifications are living with their parents in their early twenties, even though many are likely to have left home at an earlier age to attend higher education. Relative stability in the proportions living with a parent also masks changing patterns of living arrangements among young adults living away from home. Over the past twenty years there has been a move away from living in a new family (especially a couple) and a move towards living outside a family (either alone or sharing with others). Moreover, although a minority are living outside a family at a given point in time, many more are likely to have experienced this type of living arrangement at some point during young adulthood. ${ }^{30}$

With regard to housing opportunities for these young adults, the decreased affordability of owner occupation has been well documented although the affordability of privately rented accommodation has actually improved over this period as the private rented sector has expanded. ${ }^{31}$ As noted by Rugg and Rhodes (2008), compared to buying a property, the private rented sector allows access to better quality housing in better locations, for example central locations close to work, nightlife and shops. ${ }^{32}$ The trends shown in this article suggest that the demand for privately rented housing for both students and young professionals will continue to increase, especially among those living outside a family. At the same time, data from the Labour Force Survey have highlighted large regional differences in the living arrangements of young adults and hence regional differences in the demand for such housing.

The results suggest that the transition to residential independence among young adults is becoming increasingly protracted and reversible for all groups. At the oldest ages examined here - those in their early thirties - it is the most economically disadvantaged, for example those with no educational qualifications and the unemployed, who are most likely to remain living within the parental home, suggesting that this is the result of external constraints. However, among those in their twenties we have seen some narrowing of socio-economic differentials in the likelihood of living with a parent, which is likely to relate to young adults returning home after completing their higher education. It might also be related to the increased diversity of those with degree-level education in terms of other indicators of socioeconomic circumstances, arising from the continued expansion of the higher education system.

Another factor contributing to socio-economic differentials in living arrangements is that average ages at partnership formation and childbearing are higher for more socio-economically advantaged young adults. Related changes in the normative timing of entry into stable partnerships and parenthood mean that many more advantaged young adults are not ready to 'settle down' during their twenties and are likely to return to the parental home before setting off once more. For this latter group of 'emergent adults', living with a parent may often be the preferred option until partnership or family formation.

In order to understand these trends better and to investigate the role of specific factors such as increasing levels of student debt, further quantitative analysis of longitudinal data and qualitative research are required. Longitudinal data would, in particular, allow investigation of the impact of 'boomerang children' returning to the parental home in early- or mid-adulthood on the trends reported in the present article. 


\section{Key findings}

- Over the past 20 years there appears to have been virtually no change in the percentage of young adults aged 16-34 living with their parents. However this average picture masks changes in the propensity to live in the parental home in different age groups. Living in the parental home has become less common among young adults in their early twenties. In contrast, young adults in their in their mid-twenties and early thirties were more likely to be living with their parents in 2008 than was the case in 1988

- On leaving the parental home, there has been a shift away from living with a partner in early adulthood and a move towards living outside a family, either alone or sharing with others.

- Substantial regional differences in living in the parental home are apparent, with a particularly high prevalence in Northern Ireland, Strathclyde, West Midlands Metropolitan County and Outer London. Explanations for such patterns are likely to vary greatly between regions.

- Young adults - particularly men - who are unemployed have become increasingly likely to be living in the parental home during their early twenties.

- More young adults with degree-level education are living with their parents in their early twenties, which may be related to returning to the parental home on completion of higher education.

- Among those in their early thirties, those without educational qualifications and men classified as economically inactive are most likely to be living within the parental home and this trend has become more pronounced over the past two decades.

Future work might also include taking the family type of the parental home into account when examining changes in the living arrangements of young adults. ${ }^{33}$ In addition, an important issue to consider is the potential effect of recent international migration patterns, especially since the expansion of the European Union in 2004, on the living arrangements of young adults. Work to address these and other issues relating to changes in living arrangements is ongoing as part of the programme of research being undertaken at the ESRC Centre for Population Change.

\section{Acknowledgements}

This research is funded by ESRC Grant number RES-625-28-0001. The Centre for Population Change is a joint initiative between the University of Southampton and a consortium of Scottish Universities in partnership with ONS and GROS. The findings, interpretations, and conclusions expressed in this article are entirely those of the authors and should not be attributed in any manner to ONS or GROS.

The Labour Force Survey is conducted by the Office for National Statistics and the Northern Ireland Statistics and Research Agency. Access to the data is provided by the UK Data Archive. Thanks are due to James Crone and Addy Pope at EDINA and David Martin at the University of Southampton for assistance with producing the maps used in this article.

\section{Notes and References}

1 Corijn M, Klijzing E (2001) Transitions to adulthood in Europe. Kluwer Academic Publishers, Dordrecht: London.

2 Furlong A, Cartmel F (1997) Young people and social change: individualization and risk in late modernity. Open University Press: Buckingham.

3 Holdsworth C and Elliott J (2001) 'The timing of family formation in Britain and Spain', Sociological Research Online, 6(2), 49-72.
4 Iacovou M (2002) 'Regional differences in the transition to adulthood', Annals of the American Academy of Political and Social Science, 580, 40-69.

5 European Commission/Eurostat (2008) The life of women and men in Europe: a statistical portrait. Office for Official Publications of the European Communities, Luxemburg.

6 Billari FC, Philipov D and Baizan P (2001) 'Leaving home in Europe: the experience of cohorts born around 1960', International Journal of Population Geography, 7, 339-356.

7 Office for National Statistics (2007) Social Trends 37. Palgrave Macmillan: Basingstoke.

8 Bynner J, Elias P, McKnight A, Pan H and Gaelle P (2002) Young people's changing routes to independence. Joseph Rowntree Foundation: York.

9 Jones G (2002) The youth divide: diverging paths to adulthood. Joseph Rowntree Foundation, York. Available at: www.jrf.org.uk/sites/files/jrf/1842630814.pdf.

10 Ford J, Rugg J and Burrows R (2002) 'Conceptualising the contemporary role of housing in the transition to adult life in England', Urban Studies, 39(13), 2455-2467.

11 Office for National Statistics (2009) Social Trends 39, Table 3.9. Palgrave Macmillan: Basingstoke.

12 Higher Education Funding Council for England (2009) Patterns in higher education: living at home. Report 9/20. Available at: www.hefce.ac.uk/pubs/hefce/2009/09 20/.

13 Ashton D, Maguire M and Spilsburg M (1987) 'Labour market segmentation and the structure of the youth labour market,' in Ashton P and Brown D, eds., Education, unemployment and labour markets, Falmer: London, 160-178.

14 Leacker D (2009) 'Unemployment: trends since the 1970s', Economic \& Labour Market Review, 3(2), 37-41.

15 Furlong A (2006) 'Not a very NEET solution: representing problematic labour market transitions among early school-leavers', Work Employment and Society, 20(3), 553-569.

16 Wilcox S (2005) 'Trends in housing affordability,' in Regan S, ed., The great divide: an analysis of housing inequality, Shelter: London, 117-144.

17 Arnett JJ (2000) 'Emerging adulthood - A theory of development from the late teens through the twenties', American Psychologist, 55(5), 469-480.

18 The LFS questionnaire includes a question asking whether any household members are currently living in halls of residence. Since 1996, these individuals have been included as eligible household members. However, given that the information relating to these individuals tended to be based on 'proxy' responses and the small number of such cases, these cases are excluded from the analysis. These cases represent 0.6 per cent of those aged 20-34 years in 1998 and 1.0 per cent of those in this age group in 2008 .

19 Wainman G, Ambrose F and Jefferies J (2005) Focus on People and Migration, 2005. Available at: www.statistics.gov.uk/focuson/migration.

20 Berrington A and Murphy M (1994) 'Changes in the Living Arrangements of Young-Adults in Britain During the 1980s', European Sociological Review, 10(3), 235-257.

21 Full-time students are identified using the 'current student' variable, representing around 10 per cent of men and women aged 20-34 years. Students are defined as such even if they are not defined as students based on the original economic activity question. In the 2008 LFS, 38 per cent of full-time students aged 20-34 years are classified as 'in employment' using the International Labour Organisation definition, the majority of whom (76 per cent) are working part time. In addition 13 per cent of this age group are part-time students, defined as those working towards a qualification but not classified as full-time students. Most ( 85 per cent) of these part-time students are also in employment. Part-time students also tend to have more similarities to non-students than to full-time students in terms of their reasons for economic inactivity [Tyrrell K (2003) 'Economic activity among students', Labour Market Trends, 111(12), 613-621]. 
22 In the 2008 LFS, 'other' qualifications include work-related or vocational qualifications, professional qualifications, foreign qualifications and other undefined qualifications. Around a third of these comprise GCSEs below grade C, City and Guilds, Level-1 NVQs and similar UK-based academic or vocational qualifications. A further 44 per cent of respondents in the 'other' category have foreign qualifications. In 1988 the composition of the 'other' category of highest qualification is less explicitly defined. However, around 9 per cent of young adults in this category in 1988 were born outside the UK, among whom 46 per cent were 18 years or older on first arrival in the UK. Therefore, foreign qualifications are likely to represent at a much smaller proportion of this 'other' category in 1988 than in 2008.

23 We do not consider those aged under 20 due to the fact that many 19 year old students are likely to be first years living in communal halls of residence and hence not part of the LFS sample. We split up the 20-24 age group into 20-21 and 22-24 since many young adults will leave full time education at ages 20 and 21 . Hence from age 22 onwards the majority of those who reach degree level qualifications will have achieved this.

24 Higher Education Funding Council for England (2009) Regional profiles of higher education 2007. Report 07/18. Available at: www.hefce.ac.uk/pubs/hefce/2007/07_18/.

25 Champion T (2005) 'Population movement within the UK,' in Chapell R, ed., Focus on People and Migration, Palgrave Macmillan: Basingstoke, 92-114.

26 Dennett A and Stillwell J (2009) 'Internal migration in Britain, 200001, examined through an area classification framework', Population, Space and Place, Early view - published online on May 62009.
27 Note that the percentages living with their parents obtained from the LFS are higher than those from the Northern Ireland Continuous Household Survey (CHS) [Northern Ireland Statistics and Research Agency (2008) Continuous Household Survey 2007/8. Report Bulletin 7. Available at: www.csu.nisra.gov.uk/CHS\%20Bulletin\%20 $200708 \% 20-\% 20$ Final.pdf ]. For example the percentage of men and women living with a parent was 34 per cent and 15 per cent for those aged 25-29 in the CHS (compared to 44 per cent and 19 per cent in the LFS). However, this difference may not be a statistically significant difference, given the relatively small size of the Northern Irish sample within the LFS, once it is tabulated by sex and age. It is also unclear how the CHS estimate was obtained that is, using a relationship grid or by using relationship to household reference person.

28 General Register Office for Scotland (GROS) (2009) Glasgow and Clyde Valley Migration Report. Available at: www.gro-scotland.gov.uk/files2/ stats/migration/glasgow-clyde-valley-migration-report.pdf.

29 Fleming A (2005) Statistics on Migration'. Occasional Article No. 11. General Register Office For Scotland.

30 Heath S (2009) 'Young, free and single? The rise of independent living,' in Furlong A, ed., Handbook of youth and young adulthood, Routledge: Oxford, 211-216.

31 Wilcox S (2008) Can't Supply: Can't Buy. The Affordability of Private Housing in Great Britain - A Summary Report. Hometrack: London.

32 Rugg J and Rhodes D (2008) The private rented sector: its contribution and potential. Centre for Housing Policy, University of York.

33 Mitchell B, Wister A and Burch T (1989) 'The family environment and leaving the parental home', Journal of Marriage and Family, 51(3), 605-613. 